\title{
Relationship between Lignin Content and the Durability of Wood Pellets Fabricated Using Larix kaempferi C. Sawdust ${ }^{1}$
}

\author{
In Yang ${ }^{2,3} \cdot$ Hanseob Jeong ${ }^{4} \cdot$ Jae Jung Lee ${ }^{4} \cdot$ Soo Min Lee $\mathbb{D}^{4, \dagger}$
}

\begin{abstract}
This work was conducted to examine the relationship between lignin content and the durability of larch (LAR) pellets. LAR sawdust was immersed in tap water (TW), sulfuric acid (AC) and sodium hydroxide (AK) solutions, and then the immersed sawdust was used for pellet fabrication. Klason lignin (KL) content of the immersed LAR, contents of soluble lignin (SL) and monomeric sugars liberated from the immersion of LAR, and durability of LAR pellets were measured. KL content decreased as the concentration of AC and AK solutions increased, but glucose content increased with increase in AC and AK concentration. Durability of wood pellets fabricated using non-immersed LAR sawdust was the highest, followed by those made using TW-, AK- and AC-immersed sawdust. LAR pellets became more durable as the concentration of KL and SL increased, but a significant positive correlation was found only between pellet durability and KL content. Through the fluorescent microscopic observation and SEM-EDX analysis, it was verified that lignin content of non-immersed LAR pellets was higher than that of AC- and AK-immersed LAR pellets. These results suggest that lignin might contribute to an increase in inter-particle bonding in wood pellets.
\end{abstract}

Keywords: larch, immersion, lignin, pellet, durability, energy dispersive X-ray analysis

\section{INTRODUCTION}

Wood pellets are the largest internationally traded solid bio-fuel today because they are easier to store and handle than wood chips or agricultural residues (Sikkema et al., 2011).

They also have a low moisture content and relatively high energy density and low emission of greenhouse gas as opposed to that of coal and petroleum (Kang et al., 2018) The demand of renewable energy in Korean energy market was connected to the increase of wood pellet import. According to Forest Biomass Energy Association, Korea imported approximately 3million tons of wood pellets in 2018 (FBEA, 2018; Yang, 2018).

Wood pellets are generally made from mechanical wood processing by-products such as sawdust, grinding

${ }^{1}$ Date Received July 17, 2018, Date Accepted January 16, 2019

2 SCION, Te Papa Tipu Innovation Park, 49 Sala Street, Private Bag 3020, Rotorua, 3046, New Zealand

${ }^{3}$ Department of Wood and Paper Science, Chungbuk National University, Chungdae-ro 1, Seowon-gu, Cheongju, Chungbuk, 28644, Republic of Korea

${ }^{4}$ Division of Wood Chemistry Research, National Institute of Forest Science, 57 Hoegi-ro, Dongdaemun-gu, Seoul, 02455, Republic of Korea

† Corresponding author: Soo Min Lee (e-mail: lesoomin@gmail.com, ORCID: 0000-0002-4214-5094) 
dust and cutter shavings. In the pelletizing process, the raw materials are compressed by rollers through the holes of a die, and then converted to cylindrical wood pellets by the thermal softening and self-bonding of individual wood particles (Bergström et al., 2008). Wood pellets are thus nearly identical to a binderless wood composite, and consequently can be worn out or fragmented into small pieces by compression, impact or shear forces during handling, transportation and storage (Kaliyan and Morey, 2009). For example, Hill and Pulkinen (1998) reported that pellet breakage reached approximately $30 \%$ of total pellets weight after transport. As a result, it is very important for pellet producers to offer consumers sufficiently strong and durable pellets.

The strength and durability of wood pellets depends on the forces that bond or mechanically interlock the individual wood particles during the densification process. The binding forces can be broadly categorized into solid bridges, attraction forces between solid particles, mechanical interlocking bonds, adhesion/cohesion forces and interfacial forces/capillary pressure (Kaliyan and Morey, 2008). These forces are influenced by raw material type, moisture content, shape and particle size as well as densification process variables such as densification conditions, die dimension, binder addition and gap size between the rollers and die (Obernberger and Thek, 2004; Mani et al., 2006; Li and Liu, 2000; Stakl et al., 2004).

In addition these variables, the chemical constituents of the wood material also significantly impact the strength and durability of wood pellets. In particular, lignin, a natural binding material of wood, greatly affects wood strength and durability. For example, high lignin content in the woody materials used for pellet production led to more durable pellets, because lignin acts as an adhesive that binds the wood particles together (Kaliyan and Morey, 2009; Lehtikangas, 2001). However, sufficient heating of the wood particles is necessary to activate lignin. The inherent lignin, which is softened or activated by the heat of compression during the pelletizing process, is responsible for the lignin solid bridge or auto-adhesion that largely contributes to wood pellet durability (Bradfield and Levi, 1984; Wilson, 2010). Use of lignin as a binder or additive in wood pellet production increased the durability of wood pellets, similar to how the adhesive resin is used in the production of particle- and fiber-boards (Tarasov et al., 2013; Ahn et al., 2014). Lignin is known to increases the durability of wood pellet by drawing the wood particles closer together, simultaneously increasing intermolecular bonding and allowing miscible constituents to flow together. Several studies, however, still showed more or less ambiguous results which the addition of lignin didn't increase the durability significantly (Ahn et al., 2013; Min and Um, 2017; Wistara et al., 2017, Yang et al., 2017a).

Yang et al. (2017b) also showed other clues for the role of lignin in wood pellet. They prepared wood pellets of three different species such as Mongolian oak, Korean red pine and pitch pine. In comparison of durability, Mongolian oak and Korean red pine showed similar results as $96.0 \%$ and $96.2 \%$, respectively. Pitch pine, however, was $91.8 \%$ although lignin content of pitch pine is $6 \%$ higher than that of Mongolian oak. The role of lignin as a natural binder or as an additive in the pelletizing process of wood materials is well documented by several researchers. However, nobody have investigated studies the durability of wood pellets fabricated using delignified biomass raw material. Therefore, this research was focused on understanding whether the durability of wood pellets decreases when the pellets are fabricated using raw material delignified by dilute acid/alkali solutions. Larch (LAR, Larix kaempferi $C$ ) sawdust was immersed in dilute acid/alkali solutions, and then the lignin content of the sawdust was evaluated using the Klason and acid soluble methods. Subsequently, wood pellets were fabricated 
In Yang - Hanseob Jeong - Jae Jung Lee - Soo Min Lee

using the sawdust, and then the durability of the pellets was evaluated.

\section{MATERIALS and METHODS}

\subsection{Raw materials}

LAR kindly provided by the central distribution center of the National Forestry Cooperative Federation (Yeoju, South Korea), was used as the raw material for this study. LAR trees were grown throughout Kyungki and Gangwon districts. LAR sawdust was prepared by the lumbering process of the LAR trees. The LAR sawdust was screened through two sieves with 1.41-mm (18 mesh) and 3.17-mm (8 mesh) pores. Particles $(1.41 \mathrm{~mm}<$ size of sawdust $<3.17 \mathrm{~mm})$ obtained by screening were used as the raw material for LAR pellet fabrications.

\subsection{Immersion treatment}

To examine the relationship between lignin content and the durability of LAR pellets, we tried to selectively extract hemicellulose or lignin from biomass using by respectively dilute acid or alkali. LAR sawdust was immersed in tap water (TW), 10 and $20 \mathrm{~kg} / \mathrm{m}^{3}$ solutions of sulfuric acid (AC-1\% and AC-2\%) and sodium hydroxide (AK-1\% and AK-2\%) for 24, 72 and $120 \mathrm{~h}$ under ambient temperature. For example, LAR sawdust (70 g) was immersed in $600 \mathrm{ml}$ of each solution. Before immersion, sawdust was evacuated using an aspirator in desiccators for $30 \mathrm{~min}$. The immersed sawdust was dried to a level of $\mathrm{H}_{2} \mathrm{O}=10 \pm 0.5 \%$; hereinafter we will refer to the mass fraction of water as moisture content (MC). The sawdust was placed in a sealed plastic bag and stored in a refrigerator before use.

Each solution obtained from the immersion treatment was filtered through filter paper (No. 2, Adventec, Kyoto, Japan) to measure the contents of monomeric sugars and soluble lignin (SL) eluted from the immersion of LAR sawdust. After filtering, the immersed solution $(10 \mathrm{ml})$ was placed into a vial, and then stored at $4{ }^{\circ} \mathrm{C}$ until needed.

\subsection{Analysis of Klason lignin, soluble lignin and monomeric sugars}

LAR sawdust was ground into powder by a pulverizer, and then screened through a sieve with a pore size of $0.42 \mathrm{~mm}$ (60 mesh). The powder (0.3 g) was put into autoclavable glass tubes along with $5 \mathrm{ml}$ of $72 \%$ sulfuric acid. The tubes were placed into a $30{ }^{\circ} \mathrm{C}$ water bath for $1 \mathrm{~h}$ while swirling each tube once every ten minutes. Following heating, the solution in the tube was taken out of the water bath, diluted to $4 \% \mathrm{H}_{2} \mathrm{SO}_{4}$, and then autoclaved for $1 \mathrm{~h}$. Once the autoclave cycle was finished, the solution was filtered into a 500-ml Erlenmeyer flasks using by a filtering crucible (1G4). Following filtering, the sawdust remaining in the crucible was dried overnight, and assumed to be the amount of lignin (Klason lignin) in the sample on a mass basis.

The content of SL in the solution obtained after the immersion treatment of LAR sawdust was determined at $205 \mathrm{~nm}$ using an UV-visible spectrophotometer (UV-1601PC, Shimadzu, Kyoto, Japan). Prior to the determination, the immersed solution was properly diluted with distilled water (TW, AC-1\% and AC-2\%: 1/30; AK-1\% and AK-2\%: 1/150 and more) to obtain absorbance of each sample between 0.4 and 0.7. SL content was calculated according to the following equation;

$$
\begin{aligned}
& \text { Soluble lignin (\%) } \\
& \begin{array}{l}
=\frac{\mathrm{UV}_{\text {absorbance }} \times \text { Volume }_{\text {immersedsolution }(\mathrm{ml})} \times \text { Dilution factor }}{\varepsilon \times \mathrm{W}_{\text {initialdrybiomass }(\mathrm{g})}} \\
\quad \times 100 \\
(\varepsilon=\text { absorptivity, equal to } 110 \mathrm{~L} / \mathrm{g} \cdot \mathrm{cm})
\end{array}
\end{aligned}
$$


The amount of reducing sugars liberated by the immersion treatment of LAR sawdust was determined by high performance liquid chromatography (HPLC, Dionex Ultimate 3000, Dionex, Palo Alto, CA, USA). The HPLC was equipped with an Aminex 87P column (Bio-Rad, USA) and was used at $80^{\circ} \mathrm{C}$ with a $0.5 \mathrm{ml} / \mathrm{min}$ flow rate of deionized water as an eluent(NREL. A refractive index detector (Shodex RI-101, Shodex, Japan) was used to quantify monomeric sugar contents. Standard solutions of different sugars, such as glucose (Glu), xylose (Xyl), galactose (Gal), arabinose (Ara) and mannose (Man) (Sigma-Aldrich Co., St. Louis, MO, USA), were prepared for determining calibration curves. Peaks were identified by comparing peak retention times and assessing the concentrations corresponding to the different peaks. These analyses were performed in triplicate.

\subsection{Fuel characteristics}

Moisture and ash contents of each specimen were determined by the ASTM D 4442-07 and ASTM E 1755-01 methods, respectively (ASTM, 2005a; ASTM, 2005b). In addition, higher heating value (HHV) was determined by burning $1 \mathrm{~g}$ of each specimen in an oxygen bomb calorimeter (Parr 6400 Automatic Isoperibol Calorimeter, Parr Instrument Inc., Moline, Illinois, U.S.A.). Computations of the HHVs accounted for the combustion of the fusing wire (White, 1987). These analyses were performed in triplicate.

\subsection{Pelletizing processes and measurement of durability}

The amount of sawdust used for the fabrication of each pellet was standardized to $1.2 \mathrm{~g}$ to minimize experimental deviations resulting from differences in pellet sizes. The sawdust was then compressed using by a single pellet press installed at the laboratory of
Chungbuk National University (Lee et al., 2013). The press consisted of a $7 \mathrm{~mm}$-diameter cylindrical die, made of hardened steel, and it was lagged using heating elements. The end of the die was plugged using a removable backstop. Pressure (1.5 MPa) was applied to the sawdust using a piston made out of hardened steel connected to a pneumatic laboratory press. The pellets were fabricated at the die temperature of $180^{\circ} \mathrm{C}$ for $3 \mathrm{~min}$. The average diameter and length of the wood pellets fabricated by this process were 7 and $20 \mathrm{~mm}$, respectively. In addition, bulk density of the pellets ranged from 639 to $698 \mathrm{~kg} / \mathrm{m}^{3}$.

Wood pellets were placed in the incubation room $\left(25^{\circ} \mathrm{C}\right.$ and $\left.50 \% \mathrm{RH}\right)$ for $24 \mathrm{~h}$ prior to the durability test. The pellets (total weight $=50 \mathrm{~g}$ ) were placed in a tumbling can, and tumbled at $0.83 \mathrm{~Hz}$ for $10 \mathrm{~min}$. The tumbled pellets were then run through a $0.5-\mathrm{mm}$ sieve and weighed to the nearest thousand of a gram. Durability of the pellets was calculated as the ratio of the weight after tumbling to the weight prior to tumbling (NIFOS, 2016).

\subsection{Microscopic observations of wood pellets}

For microscopic observation, $2 \mathrm{~g}$ of phloroglucinol was initially dissolved in $80 \mathrm{ml}$ of $20 \%$ ethanol solution, and then concentrated hydrochloric acid (12 N) of 20 $\mathrm{ml}$ was added to the solution. For the preparation of the staining solution, LAR sawdust was evacuated using an aspirator in desiccators for $30 \mathrm{~min}$. The LAR sawdust was stained with the phloroglucinol-HCl staining solution for $24 \mathrm{~h}$, and washed with a sufficient amount of distilled water. The LAR sawdust was used as a raw material for the light microscopic observation of LAR pellets. LAR pellets were made from $0.2 \mathrm{~g}$ of LAR sawdust and the average pellet dimension was $2 \mathrm{~mm}$ (length) $\times 7 \mathrm{~mm}$ (diameter). The LAR pellets were examined with a fluorescence microscope 
(Axioscope A1, Zeiss, Germany).

LAR pellets were examined by a field emission scanning electron microscopy (FE-SEM, Supra 55VP; Carl Zeiss, Oberkochen, Germany) at an accelerating voltage of $3 \mathrm{kV}$. Each LAR pellet was placed on an aluminum stub- and then sputter-coated with a thin layer (approximately $20 \mathrm{~nm}$ thick) of platinum. In addition, the evacuated LAR sawdust was immersed in a $20 \mathrm{~kg} / \mathrm{m}^{3}$ solution of $\mathrm{KMnO} 4$ for $24 \mathrm{~h}$ and sufficiently washed by distilled water. After air-drying for $24 \mathrm{~h}$, the sawdust was used to fabricate LAR pellets. The outer surface of the LAR pellets was examined by energy dispersive X-ray analysis (EDX, XFlash 4000; Bruker AXS Microanalysis, Berlin, Germany) combined with SEM to quantitatively determine the distribution of lignin. The X-rays were collected using a detector fixed at a take-off angle of $35^{\circ}$, and their intensities were recorded in counts per second.

\subsection{Experimental design and statistical analysis}

LAR sawdust immersed in various solutions (TW, AC-1\%, AC-2\%, AK-1\% and AK-2\%) and times (24, 72 and $120 \mathrm{~h}$ ) was prepared first. The amounts of Klason lignin (KL) contained in LAR sawdust, SL and sugars liberated from LAR sawdust by immersion treatment were measured. In addition, the fuel characteristics of LAR pellets fabricated using the sawdust were examined. The effects of the type of the immersing solutions and immersion time on the fuel characteristics of LAR pellets were examined ( $5 \times 3$ factorial design).

The statistical analyses were conducted using the SAS software package for personal computers. One-way analysis of variance (ANOVA) was used to analyze the relationship between each variable and the durability of pellets at a $0.05 \%$ of significance level. If a significant relationship was found for a variable, the Student t-test was used to determine any significant difference between KL, SL and sugar contents and fuel characteristics of LAR pellets fabricated under each condition $(\alpha=0.05)$.

\section{RESULTS and DISCUSSION}

\subsection{Klason and soluble lignin}

The KL content of LAR sawdust was $31.60 \%$. The KL content decreased following immersion treatment of LAR. For example, KL contents of LAR immersed in TW, AC and AK solutions were 30.10, 29.06 and $28.08 \%$, respectively. The KL content was not significantly related to the type of immersing solutions (TW/AC: $\mathrm{p}=0.19$, TW/AK: $\mathrm{p}=0.08$, AC/AK: $\mathrm{p}=$ 0.09; Fig. 1). However, when the concentration of AC and $\mathrm{AK}$ solutions increased from 1 to $2 \%$, KL content significantly decreased (AC: $\mathrm{p}=0.02$, AK: $\mathrm{p}=0.04$ ).
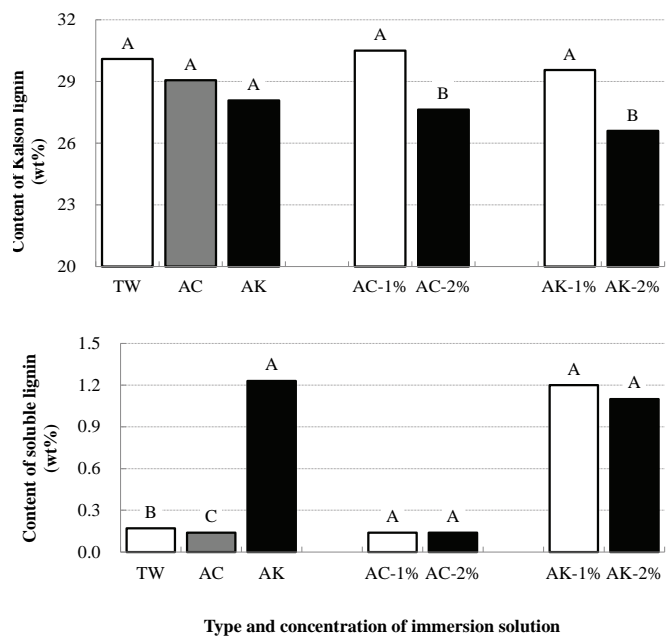

Fig. 1. Effects of type and concentration of immersing solution on the contents of Klason (top) and soluble (bottom) lignins of larch sawdust immersed in tap water (TW), $1 \%$ and $2 \%$ sulfuric acid (AC- $1 \%$ and AC- $2 \%$ ) and $1 \%$ and $2 \%$ sodium hydroxide (AK-1\% and AK-2\%) solutions. Same capital letters denote results that are not significantly different from each other at $\mathrm{p}=0.05$ (least significance difference test). 


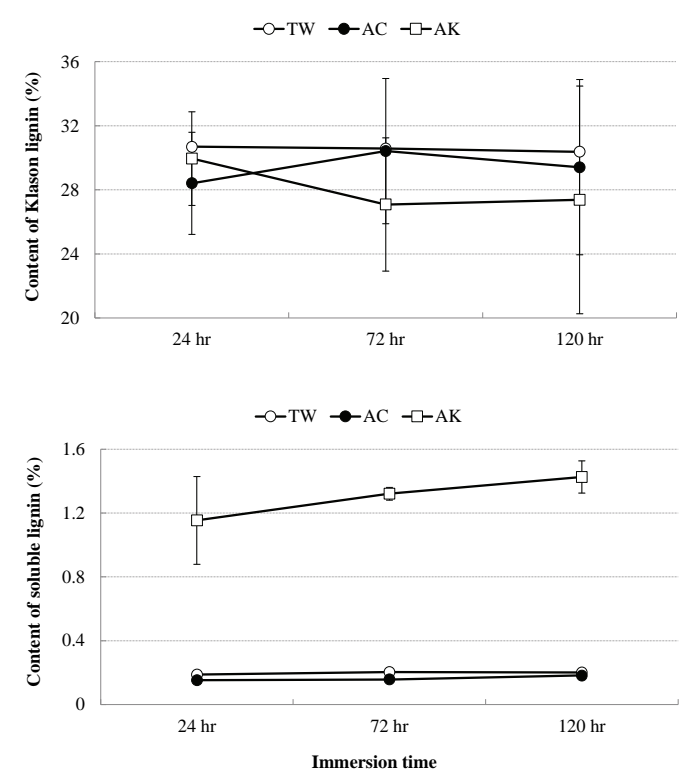

Fig. 2. Effect of immersion time on the contents of Klason (top) and soluble (bottom) lignins of larch sawdust immersed in tap water, sulfuric acid and sodium hydroxide solutions.

These results indicate that lignin decomposition of LAR might begin with the AC-2\% or AK-2\% immersion. In each immersing solution, lengthening of immersion time was not significantly related to the $\mathrm{KL}$ content of LAR (Fig. 2).

SL content was the highest in LAR sawdust immersed in the AK solution, followed by the TW and AC solutions (AK/TW: $\mathrm{p}<0.01$, AK/AC: $\mathrm{p}<0.01$, TW/AC: $\mathrm{p}<0.01$; Fig. 1). The lowest SL content of the AC immersing solution might be due to the condensation of decomposed lignin during the dilute acid-catalyzed reaction (Sannigrahi et al., 2008). However, increasing the concentration of $\mathrm{AC}$ and $\mathrm{AK}$ solutions was not significantly related to the SL content of the LAR immersing solutions (AC: $p=0.41$, AK: $p=0.26$ ). In addition, the SL content did not increase with the extension of immersion time (Fig. 2). These results show that SL content is more strongly related to the type of immersing solution than to the concentration of immersing solution or immersion time.

\subsection{Content of monomeric sugars}

The content of monomeric sugars liberated from LAR sawdust by the TW, AC and AK immersion is presented in Fig. 3. Regardless of type of immersing solutions, Glu had the highest content of all sugars liberated from LAR. The Glu content also increased when AC or AK was used as the immersing solution. These results might be closely related to the decomposition of hemicelluloses or amorphous cellulose chains. However, when the concentration of AC or AK increased from 1 to $2 \%$, Glu content did not change significantly.

Gal content was the second highest of the sugars from LAR followed by Xyl, Ara and Man (Fig. 3). These results were quite similar to the results of Lee
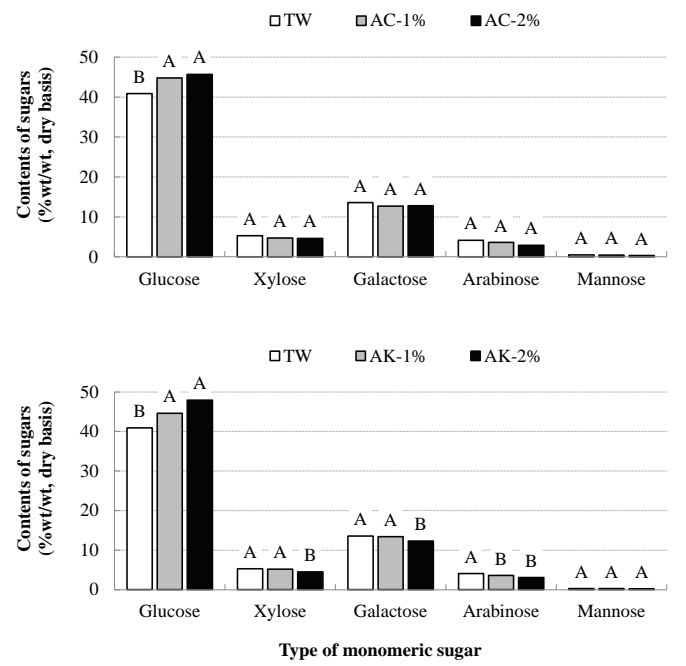

Fig. 3. Effect of type of immersing solution on the monomeric sugars content of larch sawdust immersed in tap water, sulfuric acid (top) and sodium hydroxide (bottom) solutions. Same capital letters denote results that are not significantly different from each other at $\mathrm{p}=0.05$ (least significance difference test). 
et al. (2013). Contents of the sugars were not related to the use of $\mathrm{AC}$ as an immersing solution or to the increase of its concentration. However, contents of sugars liberated from the AK immersion of LAR sawdust were quite different from those from the AC immersion. For example, Gal and Xyl contents decreased when concentration of AK solution increased from 1 to $2 \%$. In addition, amount of Ara from AK-immersed LAR was reduced. The decreases of Gal, $\mathrm{Xyl}$, Ara and Man contents might be due to the fragmentation reactions of sugars liberated by AK immersion (Sjostrom, 1983). For instance, Gal, Xyl and Ara liberated from AK-immersed LAR might be fragmented further into D-glyceraldehyde and dihydroxyacetone under an alkaline solution, resulting in decreasing sugar contents. Based on these results, holocellulose of LAR might be decomposed into sugars by the TW, AC and AK immersion, and content of the sugars is probably affected by the type and concentration of immersing solution.

\subsection{Fuel characteristics}

Table 1 shows the fuel characteristics of wood pellets fabricated using LAR sawdust that was immersed in TW, AK and AC solutions for 24, 72 and $120 \mathrm{hr}$. MC of the LAR pellets ranged between 4.8 and $6.5 \%$. The MC varied with the type and concentration of immersing solutions as well as immersion time, probably because of the MC differences in LAR sawdust used as a raw

Table 1. Fuel characteristics of wood pellets fabricated with larch sawdust immersed in tap water (TW), sodium hydroxide (AK) and sulfuric acid (AC) solutions

\begin{tabular}{|c|c|c|c|c|}
\hline \multicolumn{2}{|c|}{ Immersion condition } & \multirow{2}{*}{ Moisture content (\%) } & \multirow{2}{*}{ Calorific value $(\mathrm{MJ} / \mathrm{kg})$} & \multirow{2}{*}{ Ash content (\%) } \\
\hline Solution type & Time (hr) & & & \\
\hline \multirow{3}{*}{$\begin{array}{l}\text { Tap water } \\
\text { (TW) }\end{array}$} & 24 & $5.4 \pm 0.6$ & $19.1 \pm 0.2$ & $0.1 \pm 0.1$ \\
\hline & 72 & $4.8 \pm 0.1$ & $19.4 \pm 0.1$ & $0.2 \pm 0.0$ \\
\hline & 120 & $5.9 \pm 0.3$ & $19.5 \pm 0.3$ & $0.1 \pm 0.0$ \\
\hline \multirow{3}{*}{$\begin{array}{l}1 \%-\mathrm{NaOH} \\
(\mathrm{AK}-1 \%)\end{array}$} & 24 & $6.5 \pm 0.7$ & $18.9 \pm 0.1$ & $1.6 \pm 0.1$ \\
\hline & 72 & $6.0 \pm 0.4$ & $18.8 \pm 0.1$ & $1.6 \pm 0.0$ \\
\hline & 120 & $6.0 \pm 0.1$ & $18.6 \pm 0.0$ & $1.4 \pm 0.2$ \\
\hline \multirow{3}{*}{$\begin{array}{l}2 \%-\mathrm{NaOH} \\
(\mathrm{AK}-2 \%)\end{array}$} & 24 & $5.4 \pm 0.7$ & $18.9 \pm 0.0$ & $3.2 \pm 0.1$ \\
\hline & 72 & $5.5 \pm 0.7$ & $18.8 \pm 0.1$ & $3.0 \pm 0.1$ \\
\hline & 120 & $6.5 \pm 0.7$ & $18.3 \pm 0.2$ & $3.2 \pm 0.2$ \\
\hline \multirow{3}{*}{$\begin{array}{l}1 \%-\mathrm{H}_{2} \mathrm{SO}_{4} \\
(\mathrm{AC}-1 \%)\end{array}$} & 24 & $5.5 \pm 0.5$ & $19.4 \pm 0.3$ & $0.2 \pm 0.1$ \\
\hline & 72 & $5.5 \pm 0.7$ & $18.8 \pm 0.1$ & $0.3 \pm 0.0$ \\
\hline & 120 & $6.0 \pm 0.5$ & $18.7 \pm 0.1$ & $0.2 \pm 0.1$ \\
\hline \multirow{3}{*}{$\begin{array}{l}2 \%-\mathrm{H}_{2} \mathrm{SO}_{4} \\
(\mathrm{AC}-2 \%)\end{array}$} & 24 & $5.9 \pm 0.1$ & $18.4 \pm 0.1$ & $0.2 \pm 0.1$ \\
\hline & 72 & $5.0 \pm 0.4$ & $18.1 \pm 0.1$ & $0.2 \pm 0.0$ \\
\hline & 120 & $6.0 \pm 0.4$ & $17.6 \pm 0.3$ & $0.3 \pm 0.1$ \\
\hline \multicolumn{2}{|c|}{ Non-immersed larch sawdust } & $5.1 \pm 0.2$ & $19.0 \pm 0.1$ & $0.2 \pm 0.1$ \\
\hline \multicolumn{2}{|c|}{ NIFOS $1^{\text {st }}$-gradepellet $^{\mathrm{a}}$} & $\leq 10.0$ & $\geq 18.0$ & $\leq 0.7$ \\
\hline \multicolumn{2}{|l|}{ ENplus $\mathrm{A} 1^{\mathrm{b}}$} & $\leq 10.0$ & $16.5 \leq \mathrm{Q} \leq 19$ & $\leq 0.7$ \\
\hline
\end{tabular}

* Each value is the mean \pm standard deviation in triplicate.

a Standard for the quality of wood pellets designated by the National Institute of Forest Science (NIFoS).

b Specification of wood pellets for non-industrial use designated by the European Nation (EN 14961-2). 
material for wood pellets. However, all of the MC values were satisfied with the specifications of NIFoS $1^{\text {st }}-(\leq$ $10 \%)$ and ENplus A1- ( $\leq 10 \%)$ grade wood pellets, which were designated by National Institute of Forest Science and European Nation, respectively.

HHV of LAR immersed in TW, AC and AK solutions is shown in Table 1. Average HHV of TW-, AC- and AK-immersed LAR were 19.3, 18.5 and $18.7 \mathrm{MJ} / \mathrm{kg}$, respectively. There was no significant difference between HHVs of AC- and AK-immersed LAR (AC/AK: $p=0.18$ ), but HHV of TW-immersed LAR was higher than that of AC- or AK-immersed LAR (TW/AC: $\mathrm{p}<0.01$; TW/AK: $\mathrm{p}<0.01$ ). In addition, when the concentration of $\mathrm{AC}$ and $\mathrm{AK}$ solutions increased from 1 to 2\%, HHV of AC- and AK-immersed LAR decreased from 19.0 to $18.1 \mathrm{MJ} / \mathrm{kg}$ and from 18.8 to $18.6 \mathrm{MJ} / \mathrm{kg}$, respectively (AC: $\mathrm{p}<0.01$; $\mathrm{AK}: \mathrm{p}=$ 0.04). The higher HHV of TW-, AC-1\%- and AK-1\%-immersed LAR might be associated with its high lignin content, which had a high HHV compared with that for cellulose and hemicellulose as shown in Fig. 1 (White, 1987; Rabemanolontsoa et al., 2011). In contrast, HHV of AK- and AC-immersed LAR decreased with the extension of immersion time (Table 1). These decreases are also likely to reflect the reduction of lignin content.

Ash content of non-immersed LAR was not different from that of TW-and AC-immersed LAR (TW: $\mathrm{p}=0.33$; AC $\mathrm{p}=0.08 ;$ Table 1). In addition, when the concentration of AC solution increased from 1 to $2 \%$, ash content of AC-immersed LAR did not increase (p $=0.26$ ). However, AK-immersed LAR exhibited higher ash content than any other LAR examined in this study ( $p=0.01)$. Furthermore, increasing the concentration of AK solution had a significant positive relationship with ash content. High ash content of the AK-immersed LAR might be associated with non-combusted sodium remaining after the ash testing of LAR immersed in an AK solution.

\subsection{Durability of larch pellets}

The maximum measured durability of wood pellets fabricated with non-immersed LAR sawdust was $96.9 \%$, and this durability was higher than that of any other LAR pellets tested in this study $(\mathrm{p}<0.01)$. Fig. 4 shows the relationships between type and concentration of immersing solution and the durability of wood pellets fabricated with TW-, AC- and AK-immersed LAR sawdust. TW-immersed LAR pellets had higher durability than AK- and AC-immersed LAR pellets ( $\mathrm{P}$ $<0.01$ ). These results are closely related to high lignin content of LAR sawdust used for pellet production. Lignin is well-known to perform an important role as a binder between wood particles during the pelletizing process (Back, 1987; Briggs et al., 1999). Consequently, high lignin content sawdust is a slightly better raw material for the production of durable wood pellets than low lignin content sawdust (Ahn et al., 2014). In this study, non- and TW-immersed LAR sawdust had higher lignin contents than AC- and AK-immersed LAR sawdust, resulting in a higher durability (Fig. 1).

Although there were no differences between AC- and AK-immersed LAR in terms of the contents of lignin

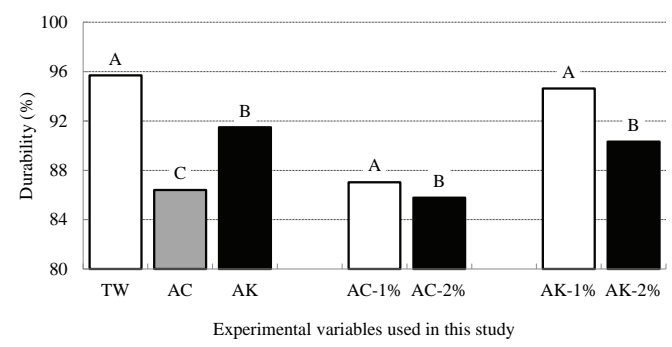

Fig. 4. Effects of type and concentration of immersing solution on the durability of wood pellets fabricated with larch sawdust, which was immersed in tap water (TW), $1 \%$ and $2 \%$ sulfuric acid (AC- $1 \%$ and AC-2\%) and $1 \%$ and $2 \%$ sodium hydroxide (AK-1\% and AK-2\%) solutions. Same capital letters denote results that are not significantly different from each other at $\mathrm{p}=0.05$ (least significance difference test). 
and sugars, durability of AC-immersed LAR pellets was lower than that of AK-immersed LAR pellets as shown in Fig. $4(\mathrm{p}<0.01)$. This result indicates that the lignin and holocellulose of AC-immersed LAR might decompose more than those of AK-immersed LAR. Consequently, the durability of AC-immersed LAR pellets was lower than that of AK-immersed LAR pellets. Similarly, as the concentration of AC and AK solutions increased, the durability of $\mathrm{AC}$ - and AK-immersed LAR pellets decreased (Fig. 4, AC: p $=0.04$, AK: $\mathrm{p}<0.01)$. These decreases might also be attributed to the increase in decomposed lignin or/and holocellulose with increasing concentrations of $\mathrm{AC}$ and AK solutions.

Fig. 5 shows the interactive effect of immersion time and the concentration of immersing solution on the durability of AK- and AC-immersed LAR pellets. Durability of AK-immersed LAR pellets was not significantly related to immersion time $(p=0.47)$, but was significantly related to the concentration of $\mathrm{AK}$ solution $(p=0.03)$. In addition, durability of ACimmersed LAR pellets decreased with the extension of immersion time; in particular, durability of AC2\%-immersed LAR pellets abruptly decreased in contrast with that of AC-1\%-immersed LAR pellets. These results indicate that the decomposition of lignin
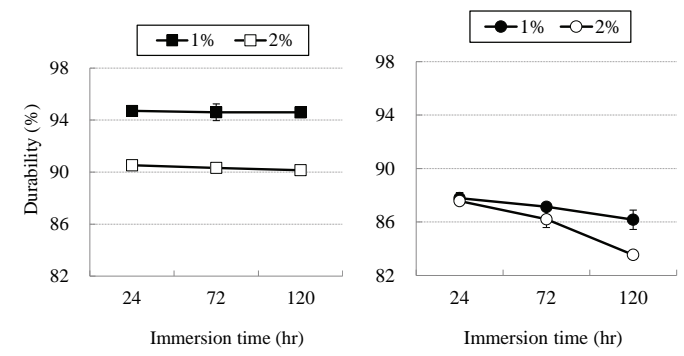

Fig. 5. Effect of immersion time and the concentration of immersion solution on the durability of wood pellets fabricated using larch sawdust immersed in sodium hydroxide (left) and sulfuric acid (right) solutions. and holocellulose in LAR might be reciprocally affected by the concentration of $\mathrm{AC}$ as well as by immersion time.

Graphs of pellet durability vs. content of KL, SL, Glu and Gal for TW-, AC- and AK-immersed LAR pellets are presented in Fig. 6. In general, LAR pellets became more durable as contents of KL, SL and Gal increased. However, a significant $\left(r^{2}=0.63\right)$ positive correlation was found only between pellet durability and KL content. Generally, the greater the lignin content of raw materials used for pellet production, the higher the durability value (Kaliyan and Morey, 2009; White, 1987). Therefore, these results indicate that high lignin content of LAR used as a raw material might positively increase the durability of the pellets. However, there
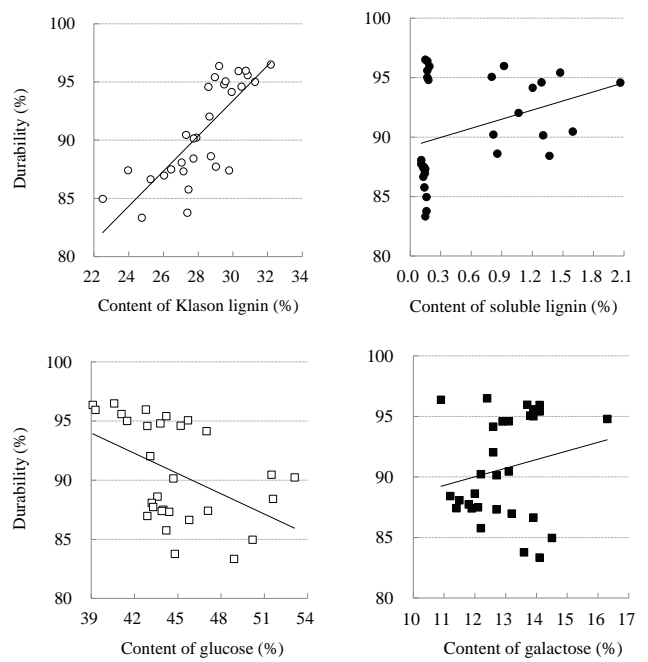

Fig. 6. Durability of wood pellets fabricated with larch sawdust, which was immersed in tap water, sodium hydroxide and sulfuric acid solutions. Results show the relationship between pellet durability and contents of Klason lignin (top-left), soluble lignin (top right), glucose (bottom-left) and galactose (bottom-right). Durability of larch pellets by content of Klason lignin $=1.51 \mathrm{x}+48.05$, $\mathrm{r}^{2}=0.63$; soluble lignin $=2.56 \mathrm{x}+89.21, \mathrm{r}^{2}=0.12$; glucose $=-0.57 \mathrm{x}+116.22, \mathrm{r}^{2}=0.21$; galactose $=0.71 \mathrm{x}+81.47, \mathrm{r}^{2}=0.04$. 
was no significant relationship between contents of SL or Gal and LAR pellet durability. Pellet durability slightly decreased with increasing Glu content, possibly due to the decomposition of hemicellulose or amorphous cellulose chains. However, there was no significant relationship between Glu content and pellet durability (Fig. 6). These inferences need to be verified in future studies using species other than LAR or increased pellets quantities.

\subsection{Microscopic observation}

In order to identify the lignin distribution on the wood pellets with non-, TW-, AC-1\%-, AK-1\%-, AC-2\%- and AK-2\%-immersed LAR sawdust, the surface of the wood pellets was examined with a fluorescence microscope (Fig. 7). The cinnamaldehyde end groups of lignin appeared to react with phloroglucinol-HCl to give a dark color (Gahan, 1984).

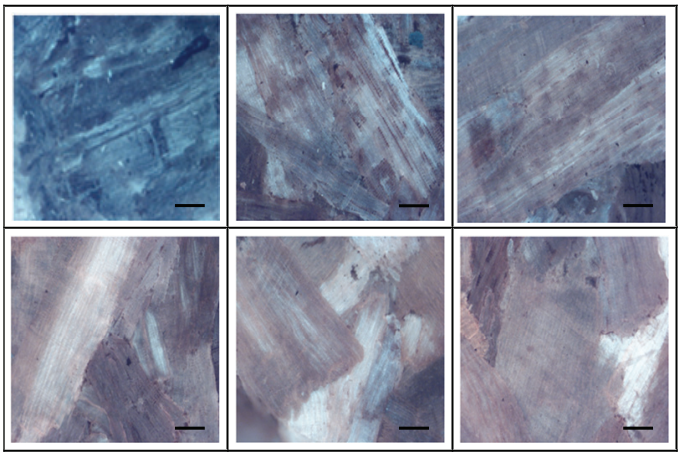

Fig. 7. Fluorescent microscopic images of the surface, which was pressured by piston, of wood pellets fabricated with non- (top-left), tap water- (top-middle), $1 \%$ sulfuric acid- (top-right), $1 \%$ sodium hydroxide(bottom-left), 2\% sulfuric acid- (bottom-middle) and $2 \%$ sodium hydroxide- (bottom-right) immersed larch sawdust. The sawdust was stained with a phloroglucinol-HCl solution for $24 \mathrm{~h}$. Bars $=2 \mathrm{~mm}$. (For interpretation of the references to color in this figure legend, the reader is referred to the web version of this article.).
More dark area can be seen on non- and TW-immersed LAR pellets than on AC- and AK-immersed LAR pellets (Fig. 7). The dark area of AC- and AK-immersed LAR pellets decreased when the concentration of $\mathrm{AC}$ and AK increased. These results indicate that lignin content of LAR decreased with increasing concentration of the immersing solutions.

Fig. 8 shows scanning electron microscopic (SEM) images of LAR pellets along with the corresponding SEM-EDX (energy disperse X-ray spectrometer) maps taken from the same area. In general, EDX mapping provides further details on the distribution of lignin. SEM-EDX analysis showed that the lignin of LAR pellets fabricated with non- and TW-immersed sawdust is widely distributed, but that with AC- and AK-

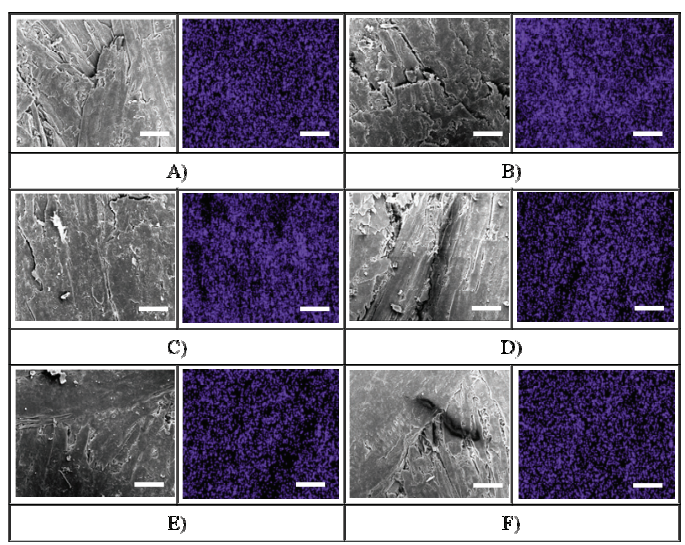

Fig. 8. Scanning electron microscopic (SEM) images of wood pellets fabricated with A) non- (top-left), B) tap water- (top-middle), C) $1 \%$ sulfuric acid(top-right), D) $1 \%$ sodium hydroxide- (bottom-left), E) $2 \%$ sulfuric acid- (bottom-middle) and F) $2 \%$ sodium hydroxide- (bottom-right) immersed larch sawdust. SEM image (left) and corresponding SEM-EDX (energy dispersive X-ray spectrometer) maps (right) taken of the same area of the wood pellets. Bright purple spots and arrow indicate the existence of lignin. Bars $=60 \mu \mathrm{m}$. (For interpretation of the references to color in this figure legend, the reader is referred to the web version of this article.). 


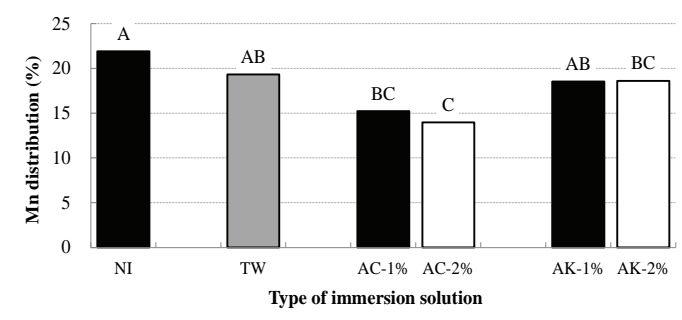

Fig. 9. Content of manganese distributed on the surface of wood pellets fabricated using larch sawdust immersed in, tap water (TW), $1 \%$ sulfuric acid (AC-1\%), 1\% sodium hydroxide (AK-1\%), 2\% sulfuric acid (AC-2\%), 2\% sodium hydroxide (AK-2\%) solutions, and non-immersed (NI) larch sawdust. The results were obtained by SEM-EDX analysis. Same capital letters denote results that are not significantly different from each other at $\mathrm{p}=0.05$ (least significance difference test).

immersed LAR sawdust is more concentrated. A quantitative measurement of the lignin distribution in the LAR pellets showed that the amount of lignin was related to the type of immersing solutions (Fig. 9). For example, content of lignin of LAR pellets fabricated with non-immersed sawdust did not differ from that of TW- or AK-1\%-immersed sawdust (NI/TW: $\mathrm{p}=0.22$; NI/AK-1\%: $p=0.13$; TW/AK-1\%: $\mathrm{p}=0.41$ ), but was higher than that of AK-2\%- and AC-immersed sawdust (NI/AK-2\%: $p=0.03$; NI/AC-1\%: $p=0.01$; NI/AC-2\%: $\mathrm{p}<0.01$ ). In addition, lignin content of TW- and AK-1\%-immersed LAR pellets was higher than that of AC-2\%-immersed LAR pellets ( $p<0.01$ ), but there were no differences in lignin contents between AK-2\%-/AC-1\%- and AC-2\%-immersed LAR pellets (AK-2\%/ AC-1\%: $\mathrm{p}=0.10$; AK-2\%/AC-2\%: $\mathrm{p}=0.11$ ). The lignin contents were closely related to the durability of LAR pellets (Fig. 4). These results indicate that lignin might increase the inter-particle bonding in LAR pellets. However, this assumption needs to be verified in future experiments using other wood species.

\section{CONCLUSION}

This work was conducted to examine the relationship between lignin content and the durability of LAR pellets. LAR sawdust was initially immersed in TW, AC-1\%, AC-2\%, AK-1\% and AK-2\% solutions for 24, 72 and $120 \mathrm{~h}$, and then the immersed sawdust was used for pellet fabrication. The KL content in the sawdust and the contents of SL and monomeric sugars in the solution, which were used for the immersion of LAR sawdust, were then quantitatively analyzed. KL content decreased as the concentration of AC and AK solutions increased. SL content was the highest in the AK immersing solution of LAR sawdust. Regardless of type of immersing solutions, Glu content was the highest of the sugars liberated from LAR. Glu content increased with the immersion in AC and AK solutions. Gal content was the second highest of the sugars liberated from LAR followed by Xyl, Ara and Man contents. When concentration of AK solution increased from 1 to $2 \%$, Gal, Xyl and Ara contents decreased.

The MC of wood pellets fabricated with LAR sawdust, which was immersed in TW, AK and AC solutions, varied with type and concentration of immersing solutions. HHV of TW-immersed LAR was higher than that of AC- or AK-immersed LAR. HHV of the AC- and AK-immersed LAR increased with increasing concentration of $\mathrm{AC}$ and $\mathrm{AK}$ solutions. However, AK-immersed LAR exhibited higher ash content than any other LAR examined in this study, and increasing the concentration of AK solution had a significant positive relationship with ash content. The high ash content of AK-immersed LAR might be associated with the presence of non-combusted sodium remaining after the ash testing of LAR immersed in an AK solution. Wood pellets fabricated with non-immersed LAR sawdust had the highest durability, followed by those with TW-, AK- and AC-immersed sawdust. The LAR pellets became more durable with 
increases in KL, SL and Gal contents, but a significant positive correlation was found only between pellet durability and KL content. This result was verified by fluorescent microscopic observation and SEM-EDX analysis. For example, content of lignin on the surface of non-immersed LAR pellets was higher than that on the surface of AC- and AK-2\%-immersed LAR pellets. These results can be attributed to the decomposition of lignin with the TW-, AC-, and AK-immersion of LAR. This assumption needs to be verified in future experiments using different wood species or increased pellets quantities.

\section{ACKNOWLEDGMENT}

This research was conducted with the financial support of the National Institute of Forest Science (FP0900-2010-01). We wish to acknowledge Dr. Han, G.S. of the Chungbuk National University for giving us some valuable advice and Ms. Kwon, S.H. of the National Instrumentation Center for Environmental Management of Seoul National University, for helping us with the microscopic observation.

\section{REFERENCES}

Ahn, B.J., Chang, H.S., Lee, S.M., Choi, D.H., Cho, S.T., Han, G.S., Yang, I. 2014. Effect of binders on the durability of wood pellets fabricated from Larix kaemferi C. and Liriodendron tulipifera L. sawdust. Renewable Energy 62: 18-23.

Ahn, B.J., Chang, H., Cho, S.H., Han, G., Yang, I. 2013. Effect of the addition of binders on the fuel characterisitics of wood pellets. Journal of the Korean Wood Science and Technology 41(6): 475-489.

American Society for Testing and Materials.2005. Standard test methods for direct moisture content measurement of wood and wood-base materials.
In: Annual Book of ASTM Standards, ASTM International, West Conshohocken, PA, ASTM D 4442-07.

American Society for Testing and Materials.2005. Standard Test Method for Ash in Biomass. In: Annual Book of ASTM Standards, ASTM International, West Conshohocken, PA, ASTM E 1755-01.

Back, E.L. 1987. The bonding mechanism in hardboard manufacture. Holzforschung 41(4): 247-258.

Bergström, D., Israelsson, S., Öhman, M., Dahlqvist, S., Gref, R., Boman, C., Wästerlund, I. 2008. Effect of raw material particle size distribution on the characteristics of Scot pine sawdust fuel pellets. Fuel Processing Technology 89: 1324-1329.

Bradfield, J., Levi, M.P. 1984. Effect of species and wood to bark ratio on pelleting of southern woods. Forest Products Journal 34: 61-73.

Briggs, J.L., Maier, D.E., Watkins, B.A., Behnke, K.C. 1999. Effects of ingredients and processing parameters on pellet quality. Poultry Science 78: 1464-1471.

[FBEA] Forest Biomass Energy Association. 2018. The Statistical data of wood pellet import. http://www.biomassenergy.kr/ [accessed Jan. 14, 2019]

Min, C.H., Um, B.H. 2017. Effect of process parameters and Kraft lignin additive on the mechanical properties of Miscanthus pellets. Journal of the Korean Wood Science and Technology 45(6): 703-719.

Gahan, P.B. 1984. Plant histochemistry and cytochemistry - an introduction. Arlington: Academic Press, Inc.: 301.

Hill, B., Pulkinen, D.A. 1988. A study of factors affecting pellet durability and pelleting efficiency in the production of dehydrated alfafa. Saskatchewan Dehydrators Association: 25.

Kang S.B., Choi, K.S., Lee, H.H., Han, GS. 2018. 
Analysis of Emission Characteristics and Emission Factors of Carbon Monoxide and Nitrogen Oxide Emitted from Wood Pellet Combustion in Industrial Wood Pellet Boilers Supplied According to the Subsidy Program of Korea Forest Service. Journal of the Korean Wood Science and Technology 46(5): 597-609.

Kaliyan, N., Morey, R.V. 2009. Factors affecting strength and durability of densified biomass products. Biomass Bioenergy 33: 337-359.

Kaliyan, N., Morey, R.V. 2008. Binding mechanisms of corn stover and switch grass in briquettes and pellets. In: Proceeding of 2008 ASABE Annual International Meeting: 1-23.

Lee, S.M., Ahn, B.J., Choi, D.H., Han, G.S., Jeong, H.S., Ahn, S.H., Yang, I. 2013. Effects of densification variables on the durability of wood pellets fabricated with Larix kaempferi C. and Liriodendron tulipifera L. sawdust. Biomass Bioenergy 48: 1-9.

Lee. S.M., Lee, A.R., Ahn, B.J., Kim, Y.S., Yang, I., Cho, S.T. 2013. Effect of diluted $\mathrm{H}_{2} \mathrm{SO}_{4}$ and $\mathrm{NaOH}$ treatment on chemical composition of larch and yellow poplar. Journal of the Korean Wood Science and Technology 41(4): 358-373.

Lehtikangas, P. 2001. Quality properties of pelletised sawdust, logging residues and bark. Biomass Bioenergy 20: 351-60.

Li, Y., Liu, H. 2000. High-pressure densification of wood residues to form an upgraded fuel. Biomass Bioenergy 19: 177-186.

Mani, S., Tabil, L.G., Sokhansanj, S. 2006. Effects of compressive force, particle size and moisture content on mechanical properties of biomass pellets from grasses. Biomass Bioenergy 20: 648-654.

National Institute of Forest Service. 2016. Standards and Quality Grades for Forest Products: Wood pellets. NIFOS No. 2016-6, Seoul, Republic of Korea.
Wistara, N.J., Rohmatullah, M.A., Febrianto, F., Pari, G., Lee, S.H., Kim, N.H. 2017. Effect of bark content and densification temperature on the properties of oil palm trunk-based pellets. Journal of the Korean Wood Science and Technology 45(6): 671-681.

Obernberger, I., Thek, G. 2004. Physical characterization and chemical composition of densified biomass fuels with regard to their combustion behaviour. Biomass Bioenergy 27: 653-669.

Rabemanolontsoa, H., Ayada, S., Saka, S. 2011. Quantitative method applicable for various biomass species to determine their chemical composition. Biomass and Bioenergy 35(11): 4630-4635.

Sannigrahi, P., Ragauskas, A.J., Miller, S.J. 2008. Effects of two-stage dilute acid pretreatment on the structure and composition of lignin and cellulose in Loblolly pine. Bioenergy Research 1: 205-214.

Sikkema, R., Steiner, M., Junginger, M., Hiegl, W., Hansen, M.T., Faaij, A. 2011. The European wood pellet markets: current status and prospects for 2020. Biofuels Bioproducts and Biorefining 5(3): 250-278.

Sjostrom, E. 1983. Reaction of carbohydrates. In: Wood Chemistry: fundamentals and application, Arlington, Academic press, Inc.: 39-49.

Stakl, M., Granstrom, K., Berghel, J., Renstorm, R. 2004. Industrial process for biomass drying and their effects on the quality properties of wood pellets. Biomass Bioenergy 27: 621-628.

Tarasov, D., Shahi, C., Leitch, M. 2013. Effect of additives on wood pellet physical and thermal characteristics: A review. International Scholarly Research Notices - Forestry: 1-6.

White, R.H. 1987. Effect of lignin content and extractives on the higher heating value of wood. Wood and Fiber Science 19(4): 446-452.

Wilson, T.O. 2010. Factors affecting wood pellet durability. M.S. Thesis, State College: Penn State 
Relationship between Lignin Content and the Durability of Wood Pellets Fabricated Using Larix kaempferi C. Sawdust

University.

Yang, I., Chae, HG., Han, GS. 2017a. Effect of bark and drying waste liquor of Larix kaempferi used as an additive on the fuel characteristics of wood pellet fabricated with rigia pine and Quercus mongolica Sawdust. Journal of the Korean Wood Science and Technology 45(3): 258-267.

Yang, I., Kang, S.M., Kim, Y.H., Han, G.S. 2018. Preliminary survey for setting evaluation standards of wood pellet safety. Journal of the Korean Wood Science and Technology 46(5): 541-552. Yang, I., Kim, SH., Han, GS. 2017b. Effect of moisture content of sawdust and length to diameter ratio of a hole in flat-die pelletizer on the fuel characteristics of wood pellets produced with Quercus mongolica, Pinus densiflora, Pinus rigida and Larix kaempferi. Journal of the Korean Wood Science and Technology 45(4): 382-398. 